26(1), 23-36

\title{
Analysis to Customer Churn Provoker's Roles Using Call Network of a Telecom Company
}

\author{
Heuiju Chun ${ }^{a} \cdot$ Byunghak Leem $^{b, 1}$ \\ ${ }^{a}$ Department of Statistics \& Information, Dongduk Women's University \\ ${ }^{b}$ Division of Business Administration, Busan University of Foreign Studies
}

(Received October 4, 2012; Revised December 7, 2012; Accepted December 10, 2012)

\begin{abstract}
In this study, we investigate how churn customers (who play a central connector or broker role) affect other customers' churn in their call networks with ego-network analysis using call data of a mobile telecom company in Korea. As a result of investigating Reciprocal Network, we found a relationship of attrition among churn customers. Churn provokers who influence other customers' attrition exist in customer churn networks. The characteristics of churn provokers is that they play a central connector and broker role in their groups. The proportion of churn provokers increases and the churn provoker's influence increases because the network is a reciprocal one.
\end{abstract}

Keywords: Social network analysis, CRM, ego-network, customer role.

\section{1. 서론}

최근 기업들은 시장개방과 더불어 고객의 욕구는 갈수록 다양해지고 까다로워지고 있으며, 또한 동종업 체와의 경쟁은 갈수록 심화되고 있으며, 심지어 다양한 제품, 기능들의 융복합화로 업종의 장벽이 허물 어져 이종업체와도 이제 경쟁을 해야 하는 어려운 환경에 직면하고 있다. 또한 기술의 급속한 발전으로 인해 상품을 통한 마케팅 활동은 의미가 약해지게 되었으며, 마케팅의 주요 핵심 개념은 상품에서 고객 으로 전환이 되어 고객을 확보하고 유지하는 $\mathrm{CRM(customer} \mathrm{relationship} \mathrm{management)} \mathrm{중심의} \mathrm{마케}$ 팅이 기업의 경쟁력 강화의 핵심수단으로 중요하게 되었다 (Baran 등, 2008). CRM 마케팅은 기업에 도움이 되는 고객을 확보하여 성장시키며 계속 수익을 낼 수 있도록 고객을 유지하는 전략과 다양한 활 동을 의미한다. 그래서 마케팅을 하기 위한 가장 기본은 고객을 이해하는 것이며 기업이 산업에서 살아 남기 위해서는 기존 고객을 유지하는 전략이 가장 중요한 핵심이라고 할 수 있다.

고객이탈관리(customer churn management)는 고객을 유지하기 위해 가장 넓게 사용된 고객유지 전략 이다. 이탈관리의 기본 정의는 고객이 다른 경쟁업체로 옮겨갈려고 의도하는 고객들을 찾아내어 고객 이탈을 방지하는 고객관리를 의미한다. 그러한 이탈 가능고객이 정의되었을 때, 기업은 고객유지를 위

This work was supported by the National Research Foundation of Korea Grant funded by the Korean Government (NRF-2011-332-B00106).

${ }^{1}$ Corresponding author: Associate Professor, Division of Business Administration, Busan University of Foreign Studies, 15 Sukporo, Nam-gu, Busan 608-738, Korea. E-mail: bhleem@bufs.ac.kr 
해서 이탈 가능고객을 타겟으로 적극적인 마케팅 캠페인을 진행하게 된다. 특히 시장이 포화될수록 신 규고객의 확보는 더욱 어려워지고 비용은 더욱 커지게 되므로 고객유지는 더욱 더 중요하게 된다. 고 객을 확보, 성장, 유지와 이탈 등의 고객 생애주기(customer lifecycle)를 통해 고객의 생애가치를 파악 하고 고객가치가 높은 고객을 유지하는 전략은 신규고객의 확보를 통해 이익을 증대시키는 것보다 우 선적인 전략으로서 매우 중요하다 할 것이다. 그래서 기업은 기여도가 높은 즉 고객 생애가치(life time value; LTV)가 높은 고객을 유지하기 위하여, 멤버십 프로그램, 고객 로열티 강화마케팅, 고객유지 캠 페인 등 다양한 마케팅 활동에 자원과 역량을 집중하게 된다 (Gupta 등, 2006; Chun, 2008, 2010).

Reichheld (1996)는 미국 기업들이 5년마다 고객 중 절반을 잃는다고 밝히고 있다. 지금까지 은행, 카 드, 통신 업종의 많은 기업들은 고객들이 왜 경쟁사로 옮겨 가는지를 이해하고 고객 이탈이유를 분석하 는데 필사적인 노력을 기울이고 있다. 고객들이 이탈했다는 것을 이해하고 구체적으로 누가 이탈했는지 아는 것은 매우 중요하며 어려운 일이다. 더구나 이탈할 고객을 찾았다 하더라도 어떠한 전략을 통해 고 객의 이탈을 막는 것은 더욱 더 어렵다 할 것이다 (Dyche, 2002).

고객이탈을 분석하는 것은 신규고객을 확보하는 것보다 기존고객을 유지하는 것이 비용이 적게 든다는 원칙에 기반하고 있다. 1980 년대 미국 기업들은 누가 이탈하였는지에 초점을 맞추었고 1990 년 이후에 는 데이터마이닝 기법을 이용하여 이미 떠난 고객들의 특성을 현재 고객들에게 적용하여 다음에 이탈할 고객들에게 적용하여 다음에 이탈할 고객들을 찾는데 주력하였다. 요즈음 기업들은 이탈할 성향이 높 은 고객들을 분류해내기 위해 비슷한 특성을 가진 고객을 비교하는 기술을 활용하며 동시에 가치가 높 은 고객을 유지하기 위해 고객들에 대한 차별성을 찾아 고객 개인들에 대한 맞춤형 마케팅(customized marketing)을 실행하고 있다. 또한 기업들은 이탈을 막는 다양한 고객유지방법을 강구하면서도 고객가 치가 낮은 고객의 이탈을 방지하는 것보다는 고객가치가 높은 이탈가능고객을 방지하고 이탈고객의 수 를 줄이는 데에 마케팅 캠페인의 초점을 맞추고 있다. 예를 들어, 통신회사에서는 고객가치가 높은 이탈 고객에게는 더 많은 보조금을 지불할 수 있을 것이며, 은행이나 카드사 등의 금융업에서는 카드 연회비, 이체수수료 등 각종 수수료 혜택을 제공하여 그 기업의 이익에 기여도가 높은 고객을 계속 유지하고자 한다.

지금까지 고객이탈에 대한 많은 이론적 연구와 실증분석이 이루어져 왔으나 고객들의 관계 구조를 기반 으로 하는 연구는 그렇게 많지 않은 실정이다. 이에 본 연구에서는 고객들 간의 구조를 나타내는 소셜 네트워크 분석을 통해 고객 역할을 분석하고, 해지자 네트워크 분석을 통해 핵심 연결자 역할 및 중개 역할을 하는 고객이 다른 고객이탈에 어떻게 영향을 미쳤는지를 분석하고 이를 기반으로 고객 이탈 예측 및 이탈 방지를 위한 방안을 제시하고자 한다.

본 연구의 구성은 2 절에서 소셜 네트워크 분석, 3 절에서 활용방법과 적용사례를 보여주고, 마지막 4 절 에서 활용방안 및 맺음말 순으로 구성되었다.

\section{2. 고객 이탈에 대한 연구 방법론}

\section{1. 고객 특성 기반 접근법}

고객이탈에 관한 연구는 은행, 보험, 소매업과 이동통신 등 기업의 모든 업종, 영역에서 다루어 온 중요 한 문제이다. 기업들은 고객이탈의 원인을 파악하고 예측하는데 다양한 기법들을 찾아내고 다양한 응용 분야에서 적용해 왔다.

이탈모형을 중심으로 이탈을 예측하는데 가장 많이 사용하는 방법으로는 로지스틱 회귀분석(logistic regression)과 의사결정나무 접근법(decision tree based approach)이다. 로지스틱 회귀분석 모형은 데이 터를 로짓 곡선에 적합시켜 사건의 발생 확률을 예측하는데 이용되는 방법이다 (Buckinx와 Poel, 2003; 
Jones 등, 2000). 의사결정나무 방법은 클래스 라벨이나 이탈 위험을 결정하는데 이용된다. Datta 등 (2000)은 의사결정 나무를 활용한 CHAMP(Churn Analysis, Modeling, and Prediction)를 통해 이동 통신 전화 고객에 대한 이탈 요인들을 예측하였다. 또한 Hadden 등 (2006)은 고객 불만 데이터를 이용 하여 고객 이탈을 예측한 의사결정나무 접근법은 신경망이나 회귀분석 방법과 비교하여 더 좋은 결과를 입증하였다. $\operatorname{Han}$ 등 (2009)은 의사결정나무 방법을 이용하여 보험사의 고객 이탈에 대한 예측 모형을 개발하는 방법을 제시하였으며, $\mathrm{Ng}$ 와 $\mathrm{Liu}(2000)$ 는 의사결정 나무 접근법을 무슨 변수가 가장 의미 있 는 변수인지를 정의할 수 있는 분류 규칙(classification rule)을 결정하는데 사용 하였다.

Morik과 Köpcke (2004)는 보험 산업에서 보험 이탈을 예측하기 위하여 잠재 의미 분석(latent semantic analysis)을 이용하였다. 이들은 데이터의 타임스탬프(time stamp) 특성을 고려하여 예측 모형의 정확성이 개선되도록 하였다. 생존분석(survival analysis)은 사건 데이터에 시간과 수명을 모형화하는 데 사용하는 또 다른 통계적 기법 중 하나이다. 이 방법은 시간 간격 이후 생존하게 될 모집단 비율이 어떻게 되는지와 같은 질문의 대답에 적합한 방법이다. $\mathrm{Lu}(2002)$ 는 이동통신 산업에서 고객 이탈을 예 측하기 위해서 이러한 생존분석 기법을 이용하였다. 또 Mavri (2008)는 은행에서 이 생존분석 기법을 이용하여 고객의 이탈 행위를 예측하였다. Gopal과 Meher (2008)은 이탈예측으로 반응변수가 순서가 있는 집합을 가지는 기법인 순서형 회귀분석(ordinal regression analysis)을 생존분석의 대안으로 제시 했다. 이 연구는 고객이 이탈하는 시간을 예측하기 위하여 고객 생애를 순서가 있는 반응변수로 모형화 하였다. 이 영역에서 최근 연구의 한 부분은 신문 서비스의 고객 이탈 예측에서 SVM(Support Vector Machines)와 Random Forests 기법이 있다 (Coussement, 2008).

\section{2. 고객 영향력 기반 접근법}

고객 이탈은 이동통신 부문 (Dasgupta 등, 2008; Hwang 등, 2004), 은행 분야, 인터넷 서비스 제공, 온라인 게임 등에서 다루어져 왔다. 가장 일반적인 의미에서 이탈은 고객의 부분적인 혹은 완전한 결점 을 의미한다. 이동통신 산업에서는 가입자가 다른 이동통신 기업으로 떠났을 때를 이탈이라고 말한다. Keaveney (1995)는 서비스 산업서 이탈에 영향을 미치는 몇 가지 요인을 제시하고 있다. 그 요인들은 가격, 불편함, 핵심 서비스 실패, 고객 서비스 실패와 불만족 등이다. 이와 같은 요인들은 이후 Hwang 등 (2004)의 연구에서 이탈을 예측하기 위하여 고객의 경험과 고객의 특성으로 분류되었다. 결과적으로 이탈예측은 서비스, 고객, 고객과 서비스 제공자간 관계의 내재적 특성의 분석에 기반을 두고 있다. 그 러나 외형적 특성은 사회적 역할을 통해 발생하는 가치에 의해 서비스를 묘사할 수 있다. 이 가치는 통 신 네트워크의 가치는 연결된 많은 이용자들이 많을수록 증가한다는 Metcalfe 법칙에 의해 부분적으로 표현할 수 있다.

예를 들면 이동통신 제공자는 가입자의 가족이나 친구에게 할인 통화를 제공함으로써 서비스를 실제 소 셜 네트워크의 안전성 및 지속성과 연결하고 있다. 그러나 서비스 질에 대한 불만족이 가입자 소셜 네 트워크 내에서 발생한다면, 서비스 제공자는 집단적으로 그룹을 잃을 위험을 맞을 수 있다. 따라서 외 적인 사회적 특성은 서비스의 가치를 결정하는데 내재적 특성만큼 중요하다. 커뮤니티 효과를 분석하고 이해하는데 중요한 측면은 개개인의 사회적 역할과 커뮤니티에 대한 개개인의 영향력을 이해하는 것이 다. 최근의 연구는 이러한 문제를 규정하고 특성 기반 접근법을 영향력 기반 접근법과 정보 확산 접근법 으로 확장하고 있다.

\section{3. 정보 확산 기반 접근법}

소셜 네트워크 분석(social network analysis)은 개인 행위에 대한 네트워크 속성 및 연결 강도를 이해 하는데 중요한 새로운 영역으로 지금까지 복잡한 거대 규모의 네트워크가 주요 연구 대상이었다. 이러 
한 연구 모형은 무작위 네트워크 모형(random network model), 작은 세상 모형(small world model; Milgram, 1967)과 척도 없는 네트워크 모형(scale free network model) 등이 있다.

현상이나 아이디어의 확산은 전염병의 확산, 혁신의 확산, 소문의 확산과 같은 개념을 이해하기 위해 사 회학, 경제학, 마케팅과 같은 분야에서 수십 년 동안 연구되어왔다. 소셜 네트워크에서 확산을 모형화 하기 위해 사용한 대표적인 두 모형은 Linear threshold model (Granovetter, 1978)과 Independent cascade model (Goldenberg 등, 2001)이다.

Dasgupta 등 (2008)는 이동통신 네트워크에서 소셜 네트워크 분석을 사용하여 고객이탈을 예측하는 새 로운 영향력 기반 접근법을 제시하고 있다. 이들은 서비스 제공자의 네트워크에서 이탈하고자 하는 가 입자의 성향은 이미 이탈한 가입자의 수에 달려있음을 제시하였다. 이를 기반으로 현재의 이탈자들과 그들의 소셜 네트워크를 관찰하여 잠재적 이탈자들을 예측할 수 있는 SPA(spreading activation) 모형 을 제안하였다. Hill 등 (2006)은 소셜 네트워크 분석을 이용하여 마케팅 캠페인에서 목표로 하는 개개 인의 네트워크에서 영향력을 규정하고 있다. 이러한 소셜 네트워크에 기반한 확산 기반 접근법은 특성 기반 접근법과 영향력 기반 접근법의 결합인 것이다.

\section{3. 연구방법론}

\section{1. 소셜 네트워크 방법론}

소셜 네트워크 분석은 네트워크에서 행위자들 간 측정한 관계를 기반으로 사회적 관계를 실증적으로 추 론하는 연구이다 (Knoke와 Yang, 2008). 이러한 소셜 네트워크를 활용한 분석은 개별 행위자의 선택이 다른 행위자에게 어떤 영향을 미칠 것인지 그리고 그 선택은 전체 네트워크와 어떻게 연관되며 또 어떻 게 영향을 주고 받는지, 다시 이것이 개별 행위자의 차후 선택에 어떤 영향을 미치는지 등에 대한 윤곽 을 어림잡을 수 있다는 것이 소셜 네트워크 분석의 장점이다 (Kim, 2007; Sohn, 2002). 이러한 소셜 네 트워크는 사회 과학뿐만 아니라 경영학, 응용과학 등 다양한 분야에서 응용되고 있으며, 분석 방법으로 소셜 네트워크 분석이 이용되고 있다.

소셜 네트워크 분석 방법에서 네트워크 구조를 파악하기 위한 기법으로 Wasserman과 Faust (1994)은 사회적 관계의 3 개의 척도로 방향성(direction), 강도(direction)와 내용(content)을 제시하였다. 방향 성은 행위자가 관계를 보내는지 혹은 받는지를 의미한다. 방향성은 또한 누가 정보를 누구에게 보내는 지를 보여준다. 사회적 관계는 방향이 없을 수도 있다. 방향이 없는 관계는 자원 흐름의 방향과는 무관 하기 때문에 누가 발송지이고 누가 수취인인지에 대한 정보를 제공하지 않는다. 강도(strength)는 두 행 위자간 상호작용 빈도이다. 내용(content)은 행위자들 간 구체적이고 실질적인 연결을 의미한다. 다시 말해서 내용은 교환하고 있는 자원의 종류를 말한다.

소셜 네트워크 5 가지 속성은 명성(prominence), 응집력(cohesion), 범위(range), 중개(brokerage), 그 리고 구조적 등위성(structural equivalence)이라 할 수 있다. 명성은 네트워크에서 누가 권력(power)를 가지고 있는지를 혹은 누가 책임을 지고 있는지를 의미한다. 응집력은 행위자들 간 강한 사회화 관 계(직접적 연결)의 존재를 나타낸다. 범위는 행위자의 네트워크 규모를, 중개는 다른 네트워크와 연결 해 주는 것을 의미한다. 마지막으로 구조적 등위성은 한 네트워크의 구조적 지위와 그 위치가 주는 역할 이 동일한 사람들 간 관계를 의미한다. 이 5 가지는 속성은 소셜 네트워크의 특징이 될 수 있지만 계량적 이지 못하다. 따라서 이 5 가지 속성들을 계량화하기 위한 측정 변수가 필요하다.

본 연구에서 사용하는 명성을 측정할 수 있는 지표는 연결정도 중심성(degree centrality)와 근접 중심 성(closeness centrality)이다. 연결정도 중심성은 한 행위자가 다른 행위자들과 얼마만큼의 관계를 맺 
고 있는가를 통해서 그 행위자가 네트워크의 중심에 위치하는 정도를 계량화한 것으로, 한 행위자에 직 접적으로 연결되어 있는 행위자들의 합으로 얻어 진다. 높은 연결정도를 가지는 행위자는 네트워크에서 중심적인 역할을 하고 있음을 의미한다. 연결정도 중심성은 개별 수준과 기업 수준의 연결정도 중심성 을 다음과 같은 식에 의해 측정할 수 있다.

$$
C_{D}\left(p_{k}\right)=\sum_{i=1}^{n} I\left(p_{k}, p_{i}\right),
$$

여기서 $n$ 은 행위자(actor 또는 node)의 수이고, $I\left(p_{k}, p_{i}\right)= \begin{cases}1, & p_{k} \text { 와 } p_{i} \text { 가 연결 이다. } \\ 0, & \text { otherwise }\end{cases}$

근접 중심성은 직접적으로 연결된 행위자뿐만 아니라 네트워크 내 간접적으로 연결된 모든 행위자 간의 거리를 계산하여 측정한다. 이 근접중심성은 두 행위자를 잇는 가장 짧은 경로거리를 모두 더한 것에 역 수를 취한 값으로 계산한다. 짧은 거리는 적은 메시지 전달, 짧은 시간과 낮은 비용을 의미하기 때문에, 높은 근접 중심성은 정보 전달의 높은 효율성과 유사한 개념으로 볼 수 있다. 그러므로 연결정도와 근접 중심성이 높을수록 네트워크의 행위자는 높은 중심 역할을 한다. 근접중심성은 두 행위자를 잇는 가장 짧은 경로거리를 모두 더한 것에 역수를 취한 값으로 계산한다.

$$
C_{C}\left(p_{i}\right)=\frac{n-1}{\sum_{j=1}^{n} d\left(p_{i}, p_{j}\right)},
$$

여기서 $d\left(p_{i}, p_{j}\right)$ 는 행위자 $p_{i}$ 와 $p_{j}$ 까지의 거리이다.

매개 중심성(betweenness centrality)은 네트워크 내에서 한 행위자가 다른 행위자들에게 가장 빠르게 도달할 수 있는 정도를 나타내며, 이는 중재자 역할의 정도를 측정하는 것이다. 한 행위자가 다른 두 행 위자간 의사소통경로 상에 전략적으로 위치했을 때, 그 행위자는 정보 전달에 영향력 있는 힘을 가지고 있음을 의미한다. 구성원들을 매개 혹은 중재할 수 있는 위치에 있는 행위자는 네트워크에서 중요한 중 심위치에 있다고 볼 수 있고 다음과 같은 식에 의해 계산 할 수 있다.

$$
C_{B}\left(p_{k}\right)=\sum_{i=1}^{n} \sum_{j=1}^{n} \frac{g_{i j}\left(p_{k}\right)}{g_{i j}},
$$

여기서 $g_{i j}$ 는 행위자 $p_{i}$ 와 $p_{j}$ 간 최단 경로의 수, $g_{i j}\left(p_{k}\right)$ 는 행위자 $p_{i}$ 와 $p_{j}$ 간 $p_{k}$ 를 경유하는 경로의 수를 나타낸다.

\section{2. 연구 모형}

본 연구에서 제시하고자 하는 모형은 우선, 해지고객들의 자아 네트워크(ego-network)를 통하여 고객의 이탈행위와 소셜 네트워크 간의 관련성 유무를 검증하고자 한다. 여기서 자아 네트워크는 개인들을 중 심으로 표현된 네트워크를 말한다. 만일, 관련이 있다면, 이탈에 영향을 미치는 소셜 네트워크의 특성을 밝혀내고, 고객 이탈방지를 위한 보다 근본적인 대책을 제시하고자 하는데 있다. 본 연구 모형에 대한 전체적인 프로세스는 Figure 3.1과 같이 표현된다.

본 연구에서 제시하는 분석 모형을 구하는 절차는 다음과 같다.

1. 전체고객을 해지고객과 유지고객으로 구분을 한다.

2. 해지고객을 중심으로 하는 해지자 네트워크 데이터베이스를 만든다.

3. 해지자 네트워크에서 커뮤니티들을 추출한다. 


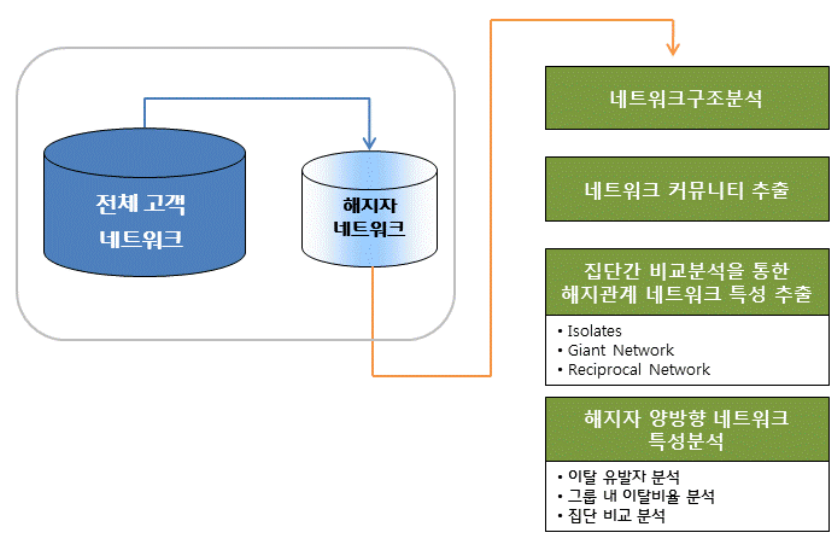

Figure 3.1. Analysis process

4. 해지자를 중심으로 하는 커뮤니티들 내에서 양방향 통화관계로 이루어진 일정 크기 이상의 네트워크 만 추출한다.

5. 커뮤니티 내에서 해지자들 간의 통화 관계가 있는 해지자(약한 관계의 네트워크, 긴밀한 관계의 네트 워크)와 통화 관계가 없는 해지자들을 중심으로 집단 비교분석을 시행한다 - 그룹 내 이탈 비율 분석, 이탈유발자 분석 등.

6. 소셜 네트워크 변수를 활용하여 고객의 이탈자들을 중심으로 하는 자아 네트워크를 통한 그룹 내에 서의 역할 유형을 제시, 규명한다 - 내부 핵심 연결자, 내부 중개자 등.

7. 근접 중심성, 매개 중심성, 연결정도 중심성 등의 소셜 네트워크 변수와 이탈과의 관계성을 분석한 다.

고객의 자아 네트워크를 통한 그룹 내 역할 유형 분석은 다음과 같이 정리할 수 있다. 한 고객의 자아 네 트워크를 분석 범위로 하여, 자아(ego)와 타자(alter)들이 맺고 있는 개별 관계의 방향성과 관계 구성에 근거하여 자아의 역할을 유형화한다. 이를 위해 각 고객 별로 자신과 수/발신이 존재하는 자아 네트워 크가 수신(in-link)을 중심으로 맺어진 관계인지, 아니면 발신(out-link)이 지배적인지, 혹은 양방향 통 화(reciprocal) 중심으로 형성되어 있는지를 판단한다. 이를 기반으로 수신, 발신, 양방의 통화에 의한 연결 수에 의해 각 고객의 역할 점수를 계산한다.

먼저 그룹 내 핵심 연결자(central connector)의 점수는 각 고객이 자신이 속한 그룹 내에서 얼마나 많 은 다른 고객들과 연결되어 있는 지를 측정함으로써, 해당 고객이 얼마나 그룹 내에서 핵심적인 역할을 하고 있는지 추정할 수 있다. 세 가지-수신 핵심 연결자, 발신 핵심 연결자, 양방 핵심 연결자-유형으로 역할자 점수를 계산한다. 우선 수신 핵심 연결자(in-central connector) 점수는 그룹 내에서의 해당 고 객의 수신 수에 의해 계산한다. 발신 핵심 연결자(out-central connector) 점수는 그룹 내에서의 해당 고객의 발신 수를 계산하여 측정한다. 마지막으로 양방 핵심 연결자(reciprocal-central connector) 점 수는 그룹 내에서의 해당 고객의 수 발신(in or out-link) 수의 계산으로 측정한다.

그룹 내 중개자(broker)의 역할 점수는 그룹 내에서 해당 고객이 매개적 위치에 존재하는 정도를 측정한 다. 이는 그룹 내 다른 두 고객을 연결하는 경로 상에 빈번하게 등장하는 고객일수록 높은 중개자 역할 점수를 얻게 된다. 이에 대한 점수는 소셜 네트워크 분석의 매개 중심성(betweenness centrality) 지표 를 통해 계산한다. 
Table 4.1. Comparison of gender in Churn Network Group

\begin{tabular}{|c|c|c|c|c|c|c|}
\hline \multirow{2}{*}{ gender } & \multicolumn{2}{|c|}{ Isolates } & \multicolumn{2}{|c|}{ Giant Network } & \multicolumn{2}{|c|}{ Reciprocal Network } \\
\hline & frequency & $\%$ & frequency & $\%$ & frequency & $\%$ \\
\hline female & 706,411 & 47.79 & 151,002 & 48.44 & 438 & 76.98 \\
\hline male & 771,629 & 52.21 & 162,677 & 51.86 & 131 & 23.02 \\
\hline $\mathrm{N} / \mathrm{A}$ & 56,509 & . & 3,518 & . & 87 & . \\
\hline total & $1,534,549$ & 100.00 & 317,197 & 100.00 & 656 & 100.00 \\
\hline
\end{tabular}

Table 4.2. Comparison of age in Churn Network Group

\begin{tabular}{|c|c|c|c|c|c|c|}
\hline \multirow{2}{*}{ age } & \multicolumn{2}{|c|}{ Isolates } & \multicolumn{2}{|c|}{ Giant Network } & \multicolumn{2}{|c|}{ Reciprocal Network } \\
\hline & frequency & $\%$ & frequency & $\%$ & frequency & $\%$ \\
\hline$<=15$ & 215,187 & 14.03 & 15,318 & 4.83 & 88 & 13.41 \\
\hline $16 \sim 19$ & 146,476 & 9.55 & 14,937 & 4.71 & 0 & 0.00 \\
\hline $20 \sim 24$ & 137,463 & 8.96 & 25,564 & 8.06 & 3 & 0.46 \\
\hline $25 \sim 29$ & 167,642 & 10.93 & 40,295 & 12.71 & 27 & 4.12 \\
\hline $30 \sim 34$ & 153,833 & 10.03 & 40,093 & 12.64 & 52 & 7.92 \\
\hline $35 \sim 39$ & 153,331 & 9.99 & 41,155 & 12.98 & 133 & 20.28 \\
\hline $40 \sim 44$ & 141,315 & 9.22 & 39,637 & 12.50 & 167 & 25.46 \\
\hline $45 \sim 49$ & 121,972 & 7.95 & 33,111 & 10.44 & 140 & 21.34 \\
\hline $50 \sim 54$ & 102,257 & 6.67 & 26,753 & 8.44 & 44 & 6.67 \\
\hline $55 \sim 59$ & 65,418 & 4.26 & 16,953 & 5.35 & 2 & 0.30 \\
\hline$>=60$ & 129,002 & 8.41 & 23,323 & 7.34 & 0 & 0.00 \\
\hline total & $1,533,895$ & 100.00 & 317,139 & 100.00 & 656 & 100.00 \\
\hline
\end{tabular}

\section{4. 분석사례 밎 결과}

본 연구에서 적용한 $\mathrm{A}$ 이동통신사의 자료는 2009 년 3 월 5 월 사이에 해지한 고객 $2,102,963$ 명을 대 상으로, 고객의 이탈행위가 소셜 네트워크로부터 영향을 받았는지를 살펴보기 위해 해지자들의 2008 년 12 월 2009 년 2 월의 3 개월 동안의 최근 3 개월 음성과 $\mathrm{SMS}$ 를 합한 해지고객의 $\mathrm{CDR}$ (call detail record) 고객 통화 자료를 가지고 해지자들 간의 네트워크 분석을 하였다. 이 중 서로 통화관계가 없는 해지자는 $70 \%$ 인 $1,534,549$ 명, 통화 관계가 있는 해지자들은 해지자의 $30 \%$ 로 568,414 명이었다. 통화 관계가 있 는 해지자들 중 317,197 명의 거대한 하나의 네트워크인 최대 규모 네트워크(Giant Network)와 해지자 들 간 양방향 네트워크를 갖고 네트워크 크기가 20 이상인 네트워크들만 추출한 656 명의 강한 통화관계 인 양방향 네트워크(Reciprocal Network)로 나누어 분석을 할 것이다. 본 연구에서는 Isolates, Giant Network, Reciprocal Network 3 집단의 비교를 통해 해지자들을 분석을 할 것이다.

\section{1. 해지자 네트워크 집단의 특성분석}

Table 4.1은 세 가지 해지자 네트워크 집단의 성별 비교를 나타내고 있다. Table 4.1을 보면 각 네트 워크의 여성비율은 양방향 네트워크 집단이 $76.98 \%$, Giant Network 집단 $48.14 \%$, Isolates 집단이 $47.79 \%$ 로 긴밀한 네트워크인 양방향 네트워크가 가장 높은 현상을 보이며 여성비율이 남성보다 4 배 정 도로 높게 나타났다. 즉 집단 이탈현상의 대부분은 여성들 사이에서 이루어지고 있음을 짐작할 수 있다.

Table 4.2는 세 가지 해지자 네트워크 집단의 성별 비교를 나타내고 있다. Table 4.2 를 보면 긴밀한 네 트워크일수록 35 49세 비중이 높아지고 있으며, 해지의 원인이 사회적 관계와 관련이 적은 Isolate 집 단인 경우는 20 대의 비중이 높음을 알 수가 있다. 
Table 4.3. Comparison of Subscription Period in Churn Network Group

\begin{tabular}{|c|c|c|c|c|c|c|}
\hline \multirow{2}{*}{ subscription period } & \multicolumn{2}{|c|}{ Isolates } & \multicolumn{2}{|c|}{ Giant Network } & \multicolumn{2}{|c|}{ Reciprocal Network } \\
\hline & frequency & $\%$ & frequency & $\%$ & frequency & $\%$ \\
\hline$>=11$ & 15,718 & 1.02 & 9,531 & 3.00 & 10 & 1.52 \\
\hline $9 \sim 11$ & 57,440 & 3.74 & 31,204 & 9.84 & 96 & 14.63 \\
\hline $7 \sim 9$ & 38,422 & 2.50 & 18,091 & 5.70 & 42 & 6.40 \\
\hline $5 \sim 7$ & 62,859 & 4.10 & 24,476 & 7.72 & 66 & 10.06 \\
\hline $4 \sim 5$ & 47,930 & 3.12 & 20,613 & 6.50 & 326 & 49.70 \\
\hline $3 \sim 4$ & 84,381 & 5.50 & 31,951 & 10.07 & 80 & 12.20 \\
\hline $2 \sim 3$ & 228,138 & 14.87 & 54,386 & 17.15 & 36 & 5.49 \\
\hline $0 \sim 2$ & 999,661 & 65.14 & 126,945 & 40.02 & 0 & 0.00 \\
\hline total & $1,533,895$ & 100.00 & 317,139 & 100.00 & 656 & 100.00 \\
\hline
\end{tabular}

Table 4.4. Connector Score Distribution of Total Call Network Customers

\begin{tabular}{ccr}
\hline connector & cum. of customers & cum. $(\%)$ \\
\hline 10.67 & 126,236 & 1 \\
7.86 & 634,517 & 5 \\
6.50 & $1,309,356$ & 10 \\
5.80 & $1,895,239$ & 20 \\
5.00 & $2,449,065$ & 25 \\
4.98 & $3,205,816$ & 30 \\
4.40 & $3,788,230$ & 40 \\
3.97 & $5,395,123$ & 45 \\
3.50 & $5,718,464$ & 50 \\
2.33 & $6,204,734$ & 65 \\
2.97 & $8,544,394$ & 70 \\
\end{tabular}

Table 4.3은 세 가지 해지자 네트워크 집단의 가입기간별 비교를 나타내고 있다. Table 4.3 을 보면 긴밀 한 네트워크일수록 가입기간이 오래된 고객 비중이 높게 나타나고 있다. 양방향 네트워크 집단의 경우 4 년 이상 가입자가 $82 \%$ 를 차지하고 있고 해지자들 간 관계가 존재하는 Giant Network의 경우 가입기 간이 3 년 이상인 고객이 $43 \%$ 를 차지하였다. 반면, Isolate 집단의 가입기간 3 년 미만 고객은 $80 \%$ 정도 이며, 이들은 가입기간이 3 년 미만인 고객으로 향후에도 휴대폰 이동통신 간 번호이동이 활발할 것으로 예상된다.

\section{2. 해지자 네트워크 집단의 역할점수 및 이탈자 분석}

Table 4.4와 Table 4.5는 해지 고객 $2,102,963$ 명과 네트워크 관계가 있는 전체 통화 네트워크에 등장하 는 통화 고객 $12,711,445$ 명을 대상으로 핵심 연결자(central connector) 점수와 내부 중개자(broker) 역 할 점수 분포를 나타낸 것이다.

Table 4.6은 세 가지 해지자 네트워크 집단들의 핵심연결자와 내부중개자 평균 역할점수와 전체 통화네 트워크 집단에서 위치를 제시해주고 있다. Table 4.6 을 보면, 전체 통화네트워크 집단에서 역할 점수 분 포를 고려할 때, 긴밀한 네트워크일수록 상위권에 속함을 보여주고 있다.

이동통신 네트워크의 해지자 네트워크에서 해지 일자 별 소그룹에 핵심 연결자 점수와 중개자 점수가 동 
Table 4.5. Broker Score Distribution of Total Call Network Customers

\begin{tabular}{ccr}
\hline broker & cum. of customers & cum. $(\%)$ \\
\hline 50.09 & 126,470 & 1 \\
31.22 & 634,503 & 5 \\
24.13 & $1,269,457$ & 15 \\
20.19 & $1,905,249$ & 20 \\
17.52 & $2,540,011$ & 25 \\
15.54 & $3,176,754$ & 30 \\
14.00 & $3,760,338$ & 35 \\
12.63 & $4,446,773$ & 40 \\
11.50 & $5,056,386$ & 45 \\
10.50 & $5,654,335$ & 50 \\
9.50 & $6,255,864$ & 55 \\
7.50 & $6,950,710$ & 60 \\
& $7,622,878$ & 65 \\
\end{tabular}

Table 4.6. Comparison of Role Score in Churn Network

\begin{tabular}{|c|c|c|c|c|c|c|}
\hline \multirow{2}{*}{ role } & \multicolumn{2}{|c|}{ Isolates } & \multicolumn{2}{|c|}{ Giant Network } & \multicolumn{2}{|c|}{ Reciprocal Network } \\
\hline & mean score & percentile & mean score & percentile & mean score & percentile \\
\hline connector & 3.82 & upper $43 \%$ & 4.08 & upper $32 \%$ & 5.19 & upper $19 \%$ \\
\hline broker & 11.76 & upper $39 \%$ & 13.04 & upper $29 \%$ & 18.85 & upper $17 \%$ \\
\hline
\end{tabular}

Table 4.7. Churn Provoker Comparison in Churn Network

\begin{tabular}{ccccccccc}
\hline & \multicolumn{2}{c}{ Isolates } & & \multicolumn{2}{c}{ Giant Network } & & \multicolumn{2}{c}{ Reciprocal Network } \\
\cline { 2 - 3 } & frequency & $\%$ & & frequency & $\%$ & & frequency & $\%$ \\
\hline churn provoker & 82,841 & 5.40 & & 35,779 & 11.28 & & $\mathbf{2 0 0}$ & $\mathbf{3 0 . 4 9}$ \\
\hline
\end{tabular}

Table 4.8. Rate of Group Which Additional Churns Occur

\begin{tabular}{rccc}
\hline & belonged & \# of groups which & rate of \\
& network groups & additional churn occurs & churn provocation \\
\hline non-provoker churns & $1,473,320$ & 246,189 & 16.71 \\
provoker churns & 424,024 & 180,770 & 42.63 \\
\hline total \# of groups & $6,063,974$ & & \\
\hline
\end{tabular}

시에 높은 고객이 존재함을 볼 수 있다. 이는 두 역할점수가 높다는 것은 본인이 해지 시에 다른 고객의 해지에 영향을 줄 수 있는 해지영향력을 가지고 있음을 의미한다. 그래서 이들을 이탈 유발자로 명명할 것이다.

Table 4.7 은 세 가지 해지자 네트워크 집단들의 이탈유발자 비율을 비교한 것이다. Table 4.7 을 보면, 긴밀한 네트워크일수록 이탈유발자 비율이 높게 나타나고 있다. 즉 관계에 의한 이탈현상은 이탈유발자 의 영향이 큰 것으로 해석할 수 있으며 소셜 네트워크분석을 활용한 이탈방지의 핵심은 긴밀한 소셜 네 트워크 내에 '잠재 이탈유발자'를 찾는 데 있다 할 것이다.

Table 4.8 은 전체 통화네트워크 중에서 이탈유발자가 해지한 경우와 그렇지 않은 경우의 추가 해지가 발 
Table 4.9. Mean Churn Rate of Groups Which Churn Provoker Belongs in

\begin{tabular}{cccc}
\hline & group & \# of groups & $\begin{array}{c}\text { mean churn rate } \\
\text { within group }\end{array}$ \\
\hline non-provoker churns & total call network group & $1,473,320$ & $5.17 \%$ \\
\hline provoker churns & $\begin{array}{c}\text { group which provoker } \\
\text { belongs in total call network }\end{array}$ & 424,024 & $10.11 \%$ \\
\hline $\begin{array}{c}\text { group which provoker } \\
\text { belongs in Giant Network }\end{array}$ & 81,058 & $11.81 \%$ \\
\hline $\begin{array}{c}\text { group which provoker } \\
\text { belongs in Reciprocal Network }\end{array}$ & 436 & $59.12 \%$
\end{tabular}

생한 그룹의 비율을 나타내고 있다. Table 4.8 을 보면 이탈유발자가 속해 있는 네트워크에서 추가 이탈 이 더욱 발생하고 있음을 알 수 있다.

Table 4.9는 이탈유발자 소속 네트워크별 그룹 평균 이탈 비율을 나타낸다. Table 4.9 를 보면 이탈유발 자가 속해 있는 그룹의 평균 이탈비율이 비이탈유발자가 속해 있는 그룹보다 크게 나타나고 있으며, 특 히 양방향 네트워크 그룹의 평균 이탈비율은 59.12 로 가장 높게 나타나고 있다.

\section{3. 양방향 해지자 네트워크 분석}

음성과 SMS 통합 통화 양방향 네트워크 집단은 20 개 이상의 크기를 갖는 15 개의 네트워크를 모아 놓은 집단들인 656 명으로 구성되어 있다. 본 연구에서는 음성과 SMS 통합의 양방향 통화 네트워크 집단의 예제로 656 명 양방향 네트워크 집단 중의 하나인 102 명의 해지자들 간의 네트워크를 Figure 4.1 의 그래 프로 표현하였다. 색상은 해지 일자 별 표현으로 빨간색은 보라색 보다 먼저 해지했음을 의미하고, 열 십자 모양은 핵심연결자와 내부중개자의 역할 점수가 평균점수보다 모두 높은 고객을 의미한다. 모양의 크기는 고객의 연령대를 의미하고 라벨은 해지 일자를 나타낸다. 큰 원 및 타원들은 해지 일자 별 소그 룹을 의미한다.

Figure 4.1를 보면 정확한 이탈현상의 인과관계를 알 수는 없지만 집단 무더기 이탈현상이 일어나고 있 음을 알 수 있다. 또한 해지 일자 별 소그룹인 큰 원을 보면 핵심연결자, 내부중개자 역할점수가 모두 높은 이탈유발자(그림에서 십자가로 표시됨)가 존재하고 있음을 알 수가 있다. 즉 긴밀한 네트워크일수 록, 이탈유발자 비중이 높고, 이들 이탈유발자와의 관계에 의한 이탈현상은 이탈유발자의 영향이 큰 것 으로 볼 수 있을 것이다.

\section{5. 활용방안 밎 맺음말}

2009 년 3 월 5 월 사이에 해지한 A 이동통신사의 고객 $2,102,963$ 명을 대상 중 해지자들 간 통화관계가 없는 고객은 $70 \%$ 이며, 이들 중 가입기간이 3 년 미만인 고객은 $80 \%$ 정도를 차지하고 있으며, 이들은 향 후에도 휴대폰 이동통신 간 번호이동이 활발할 것으로 예상된다. 해지자들 간 양방향 네트워크가 긴밀 한 네트워크 집단은 가입기간 $4 \sim 5$ 년으로 $35 \sim 49$ 세, 여성의 비중이 높게 나타났다.

해지자들 간 양방향 통화를 갖는 네트워크를 살펴본 결과, 해지자들 간의 무더기 이탈 현상을 확인할 수 있었다. 이러한 이탈 그룹에는 그룹 이탈에 영향을 주는 이탈유발자가 존재하고 있었으며, 이러한 이탈 유발자의 특징은 그룹 내에서 많은 구성원들과 연결되어 있는 핵심 연결자 역할을 하면서, 정보전달의 매개자 역할을 동시에 해내는 고객이었다. 즉 긴밀한 네트워크일수록, 이탈유발자 비중이 높고, 이들 이 


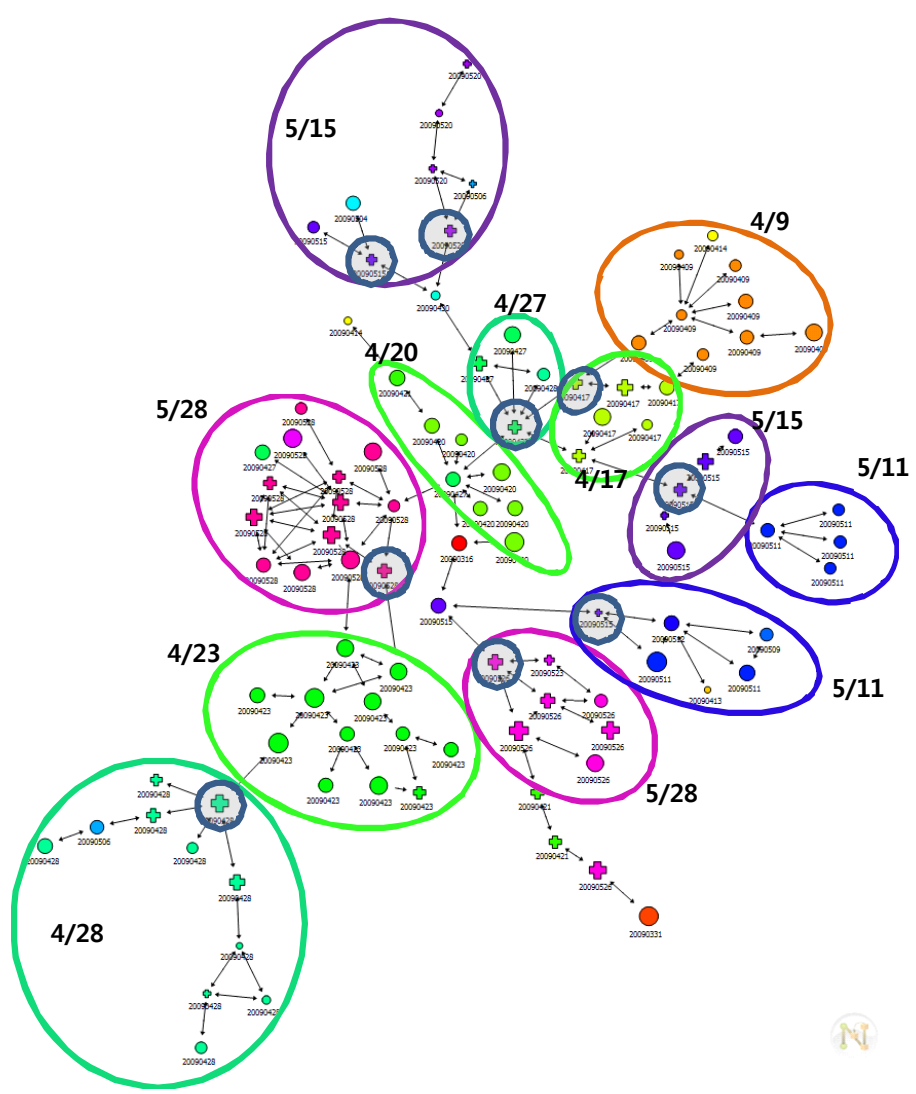

Figure 4.1. 102 Customer Churn Network: Group Separation to Churn Date

탈유발자와의 관계에 의한 이탈현상은 이탈유발자의 영향이 큰 것으로 볼 수 있을 것이다. 또한 비 이 탈유발자가 해지했을 경우, 그룹 평균 이탈율이 $5 \%$ 인데 반해, 이탈 유발자가 해지했을 경우, 그룹 평균 이탈율이 $26 \%$ 였다. 그리고 이탈유발자가 해지할 때, 추가 이탈이 발생하는 경우가 43 인데 반해, 비 이 탈유발자가 해지할 때, 추가 이탈이 발생하는 경우는 $17 \%$ 로 나타났다. 결국 이동통신회사에서의 소셜 네트워크 분석 기술을 활용한 이탈방지의 핵심은 긴밀한 소셜 네트워크 내에 존재하는 '잠재 이탈유발 자'를 찾아 이들을 대상으로 고객 이탈방지 노력을 어떻게 할 것인지가 마케팅 역량의 핵심이 될 것이 다.

현재 많은 기업에서는 이탈고객의 이탈원인을 찾아 규명을 하고 또한 이탈 가능성이 높은 고객을 찾아 이탈을 방지하는 이탈방지 프로그램이나 캠페인을 실행하고 있다. 특히 사회적 관계성이 매우 높은 고 객이 그 기업에 대한 불만이나 실망으로 이탈을 하게 되면 그 고객과 관계성이 매우 높은 주위 고객들에 게 이탈 영향 또한 크게 미칠 것으로 사료된다.

본 연구에서 얻은 소셜 네트워크 변수를 활용하여 고객유지를 위한 마케팅에 활용하면 다음과 같은 효과 를 얻을 것이다. 첫째, 네트워크 핵심 연결자 역할 점수를 활용하여 이탈가능성이 높은 고객에 대해 타 겟 마케팅을 한다면 소셜 네트워크의 확산성(diffusion)에 의해 단순한 이탈확률만 높은 고객을 타겟으 
로 하는 마케팅 보다 이탈방지의 확산효과는 더욱 커질 것이다. 가령 내부핵심 연결자 점수가 높거나 또 는 내부 중개자 점수가 높은 이탈가능성이 높은 고객을 우선으로 마케팅 대상으로 특별 관리를 한다면 그 고객중심의 네트워크의 이탈 가능성은 더욱 더 낮아질 것이다. 둘째, 본 연구에서 도출된 사회네트 워크 변수와 역할 변수들을 활용하여 고객 이탈 모형의 변수로 활용하면 이탈 가능성에 대한 정확도는 더욱 더 증대될 것이다. 세째, 더욱 더 정교한 이탈 모델과 이탈 방지의 확산성을 통해 고객 이탈방어 프 로그램 비용은 매우 줄어들 것이다.

현재 기업은 고객 가치가 높은 고객에 대해 차별성을 더욱 더 강조하고 이를 통해 여러 가지 자원의 배 분을 효율적으로 배분하고자 한다. 본 연구에서 제안하는 소셜 네트워크 방법을 활용한다면 고객 가치 를 강조하는 은행, 카드사, 통신사, 증권회사, 백화점 등 모든 업종에서, 고객 로얄티, 고객유지 및 이탈 방지 마케팅 등 다양한 영역에서 활용가능하리라 여겨진다.

\section{References}

Baran, R. J., Galka, R. J. and Strunk, D. P. (2008). Principles of Customer Relationship Management, Thomson South-Western.

Buckinx, W. and Poel, D. V. D. (2003). Customer base analysis: Partial defection of behaviorally-loyal clients in a non-contractual FMCG retail setting, European Journal of Operational Research, 164, $252-268$.

Chun, H. (2008). Customer loyalty score model development, Korean Journal of Applied Statistics, $21,1-9$.

Chun, H. (2010). Membership subscription effect and positioning study of a mobile telephone company, Journal of the Korean Data Analysis Society, 12, 973-982.

Coussement, K. (2008). Churn prediction in subscription services: An application of support vector machines while comparing two parameter selection techniques, Expert Systems with Applications, 34, 313-327

Dasgupta, K., Singh, R., Viswanathan, B., Chakraborty, D., Mukherjea, S., Nanavati, A. and Joshi, A. (2008). Social ties and their relevance to churn in mobile telecom networks. EDBT '08: Proceedings of the 11th international conference on Extending database technology, 668-677, New York, NY, USA.

Datta, P., Masand, B., Mani, D. R. and Li, B. (2000). Automated cellular modeling and prediction on a large scale, Artificial Intelligence Review, 14, 485-502.

Dyche, J. (2002). The CRM Handbook: A Business Guide to Customer Relationship Management, Addison Wesley Professional.

Goldenberg, J., Libai, B. and Muller, E. (2001). Talk of the network: A complex systems look at the underlying process of word-of-mouth, Marketing Letters, 12, 211-223.

Gopal, R. K. and Meher, S. K. (2008). Customer Churn Time Prediction in mobile telecommunication industry using ordinal regression, Advances in Knowledge Discovery and Data Mining, 5012, 884-889.

Granovetter, M. (1978). Threshold models of collective behavior, American Journal of Sociology, 83, 14201443.

Gupta, S., Hanssens, D., Hardie, B., Kahn, W., Kumar, V., Lin, N., Ravishanker, N. and Sriram, S. (2006). Modeling customer lifetime value, Journal of Service Research, 9, 139-155.

Hadden, J., Tiwari, A., Roy, R. and Ruta, D. (2006). Churn prediction using complaints data, Proceedings of World Academy Of Science, Engineering and Technology, 13, 158-163.

Han, S., Kangg, H., Choi, H., Do, J. and Shin, S. (2009). A study on development of customer attrition model in financial institution data, Journal of the Korean Data Analysis Society, 11, $279-288$.

Hill, S., Provost, F. and Volinsky, C. (2006). Network-based marketing: Identifying likely adopters via consumer networks, Statistical Science, 22, 256-275.

Hwang, H., Jung, T. and Suh, E. (2004). An LTV model and customer segmentation based on customer value: A case study on the wireless telecommunication industry, Expert Systems with Applications, 26, 181-188.

Jones, M. A., Mothersbaughb, D. L. and Beattyc, S. E. (2000). Switching barriers and repurchase intentions in services, Journal of Retailing, 76, 259-274. 
Keaveney, S. M. (1995). Customer switching behavior in service industries: An exploratory study, The Journal of Marketing, 59, 71-82.

Kim, Y. (2007). Social Network Analysis, Parkyoungsa, Seoul.

Knoke, D. and Yang, S. (2008). Social Network Analysis, 2nd, SAGE Publications.

Lu, J. (2002). Predicting customer churn in the telecommunications industry an application of survival analysis modeling using SAS SUGI27.

Mavri, M. (2008). Customer switching behavior in greek banking services using survival analysis, Managerial Finance, 34, 186-197.

Milgram, S. (1967). The Small World Problem, Physiology Today, 2, 60-67.

Morik, K. and Köpcke, H. (2004). Analysing customer churn in insurance data: a case study, PKDD'04: Proceedings of the 8th European Conference on Principles and Practice of Knowledge Discovery in Databases..

Ng, K. and Liu, H. (2000). Customer retention via data mining, Artificial Intelligence Review, 14, 569-590. Reichheld, P. F. (1996). The Loyalty Effect: The Hidden Force Behind Growth, Profits, and Lasting Value, Cambridge University Press.

Sohn, D. W. (2002). Social Network Analysis, Kyungmoonsa, Seoul.

Wasserman, S. and Faust, K. (1994). Social Network Analysis, Cambridge University Press. 


\title{
소셜 네트워크 분석을 기반으로 한 이동통신 잠재고객 이탈에 대한 연구
}

\author{
전희주 ${ }^{a} \cdot$ 임병학 $b 1$ \\ ${ }^{a}$ 동덕여자대학교 통계학과, ${ }^{b}$ 부산외국어대학교 데이터경영학과
}

(2012년 10월 4일 접수, 2012년 12월 7일 수정, 2012년 12월 10일 채택)

\begin{abstract}
요 약
본 연구에서는 국내 한 이동통신회사의 해지 고객 중심의 통화 네트워크 데이터를 가지고 고객들 간의 관계 구조를 나타내는 소셜 네트워크 분석의 일종인 자아 네트워크(Ego-Network) 분석을 통해 핵심 연결자 역할 및 중개 역할 을 하는 이탈고객이 다른 고객의 이탈에 어떻게 영향을 미쳤는지를 분석하고 이를 기반으로 고객 이탈 예측 및 이탈 방지를 위한 방안을 제시하고자 한다. 해지고객들 간 양방향 통화를 갖는 네트워크를 살펴본 결과, 해지고객들 간의 무더기 이탈 현상을 확인할 수 있었다. 이러한 이탈 그룹에는 그룹 이탈에 영향을 주는 이탈유발자가 존재하고 있었 으며, 이러한 이탈유발자의 특징은 그룹 내에서 많은 구성원들과 연결되어 있는 핵심 연결자 역할을 하면서, 정보전 달의 매개자 역할을 동시에 해내는 고객이었다. 즉 긴밀한 네트워크일수록, 이탈유발자 비중이 높고, 이들 이탈유발 자와의 관계에 의한 이탈현상은 이탈유발자의 영향이 큰 것으로 볼 수 있을 것이다.
\end{abstract}

주요용어: 소셜 네트워크 분석, $\mathrm{CRM}$, 자아 네트워크, 이탈, 고객 역할자.

이 논문은 2011년도 정부재원(교육과학기술부 인문사회연구역량강화사업비)으로 한국연구재단의 지원을 받아 연구되었음(NRF-2011-332-B00106).

${ }^{1}$ 교신저자: (608-738) 부산시 남구 석포로 15 , 부산외국어대학교 데이터경영학과, 부교수. E-mail: bhleem@bufs.ac.kr 